\title{
Torti, E.; D'Angelo, E. y Salzman, D. (2017): La carrera de docente guía estudiantil. Una paradoja educativa. Santa Fe: Ediciones UNL.
}

por Victoria Baraldi ${ }^{(1)}$ y Carina Toibero (2)

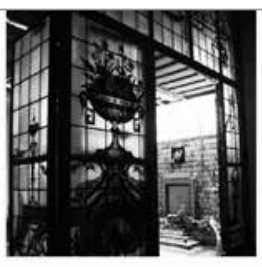

LA CARRERA DE DOCENTE GUIAA ESTUDIANTIL Una paradoja educativn

ESTELA TORTI ELSA D'ANGEL 0 DIANA SALZMAN
En nuestro país, donde el desgranamiento es un problema grave, ino es necesario un docente con una formación universitaria adecuada, que acompañe y realice un seguimiento de los alumnos a fin de ayudar a mejorar su aprendizaje? (Torti, D’Angelo y Salzman, 2017:84)

Al cierre de la edición de este número dedicado a «juventudes y educación», llegó a nuestras manos el libro de Estela Torti, Elsa María D'Angelo y Diana Salzman sobre la carrera de Docente Guía Estudiantil, de reciente publicación. Un libro que, sobre la base de la recuperación de un proyecto educativo iniciado en el año 1959 en la UNL, tiene absoluta vigencia en la actualidad. Los problemas que se pretendían resolver en aquel entonces son similares - con otras características y connotaciones - a los que se requiere resolver ahora: formar a un docente
(1) Profesora en Ciencias de la Educación (UNER), magister en Didácticas Específicas (UNL) y doctora en Educación (UNER). Profesora adjunta ordinaria en Didáctica II (UNER), profesora titular ordinaria de Didáctica General (UNL). Secretaria de investigación de la Facultad de Humanidades y Ciencias (UNL), directora de la Maestría en Docencia Universitaria (UNL) y directora de la revista Itinerarios Educativos (FHUCUNL). Ha sido directora de diversos proyectos de investigación en el área de Didáctica y ha participado en otros sobre Curriculum e Historia de la Educación. Posee numerosas publicaciones con relación a estos temas. Ha dirigido y codirigido tesis de posgrado.vbaraldi@gmail.com
(2) Profesora de Letras y estudiante avanzada de Licenciatura en Letras (FHUC-UNL). Docente de nivel medio y superior. Miembro del Consejo de Redacción de la Revista Itinerarios Educativos (FHUCUNL). Becaria en el Programa de Desarrollo Editorial de la Facultad de Humanidades y Ciencias (UNL). toiberocarina@gmail.com 
no especializado, con un perfil de mediador que pueda establecer nexos entre los estudiantes y el docente y entre la familia y la escuela para promover mejores procesos de aprendizaje y contribuir a una formación integral.

Hace ya bastante tiempo, y a propósito de la posibilidad de reconstruir el proyecto educativo del Instituto del Profesorado Básico (1959-1969) —que fuera ideado y dirigido por la profesora Ana María Caffaratti-, le hicimos una entrevista a Delia Travadelo. Esta profesora de Letras, con un rol protagónico en el proyecto, nos dijo algo así como: «aquello no era una flor exótica, era parte de un proyecto educativo». En sintonía con esto, Ramón Caropresi, al describir lo que fue inicialmente la escuela experimental Almirante Brown, nos decía: «éramos un grupo con levadura». Con ese entusiasmo y claridad, un grupo de docentes trabajó en pos de un proyecto educativo para formar docentes y jóvenes de esa generación. Sus ideas quedaron plasmadas en el Instituto del Profesorado Básico, la creación de la carrera de Docente Guía Estudiantil, la reapertura de la Facultad de Ciencias de la Educación de Paraná y la Escuela Normal Experimental Alte. G. Brown —única institución educativa que efectivamente aceptó la figura del Docente Guía Estudiantil para los cargos de directores de cursos-. Por eso es tan importante este libro, porque, si bien se analiza especialmente esta carrera de Docente Guía Estudiantil, Io hace en el marco de lo que fue un proyecto educativo más amplio.

A las autoras no les contaron esta historia, la vivieron. Dos fueron sus egresadas, y otra vivenció el modo en que estos egresados trabajaron. Ante la clausura de la carrera y los avatares que sufrieron por el reconocimiento de los títulos, tuvieron el compromiso intelectual para poder reconstruirla. Dicha reconstrucción fue un largo camino en donde recuperaron voces de sus protagonistas, recopilaron documentos, hilvanaron ideas y luego le dieron forma. Se trató de un trabajo no subsidiado, muy complejo y extenso en el tiempo, un libro de muchas estaciones reconstruido por parte de sus protagonistas a modo de legado educativo.

Este legado quedó conformado por cuatro capítulos: los antecedentes de la carrera (1); el proyecto y Plan del Profesorado Básico (2); la carrera de Docente Guía Estudiantil —donde se puede observar el diseño curricular innovador, basado en tres grandes ejes: Formación Cultural, Formación Pedagógica y Formación Científica- (3); y la experiencia en la Escuela Normal Alte. 
G. Brown (4). Además, se incorpora un extenso anexo que recupera históricamente la legislación referente al cargo, testimonios, reclamos y numerosos documentos relevantes.

En la contratapa leemos: « iNo es una paradoja que los fundamentos que dieron origen a la carrera sigan vigentes y sin embargo no haya una propuesta seria para integrar un agente con esas características?», cuestionamiento que dio origen al subtítulo del libro y que plantea un tema esencial. El término nos remite a una visible contradicción entre las demandas pedagógicas y el escaso interés de las autoridades políticas en volver factible la integración de un nuevo agente escolar que funcionara como mediador entre los diversos agentes de la comunidad educativa: profesores, alumnos, directivos y padres, "a fin de enfrentar las difíciles problemáticas adolescentes, familiares y sociales que atraviesan las escuelas actualmente» (p. 83).

Es objetivo de este libro retomar este tipo de preguntas, entre las cuales también se incluye cuestionarse: «ipor qué no fueron estimados estos profesionales para integrarlos a las distintas reformas educativas?» (p. 84) Quizá el hecho de que los egresados nunca fueran escalafonados fue uno de los motivos por los cuales cerró la carrera tan tempranamente. Revisar esto tiene validez y es pertinente porque un profesional que tenga en cuenta las nuevas formas de producción de subjetividad, los modos actualizados de funcionamiento social de los adolescentes y que pueda conceptualizar las propias prácticas, aún tiene vigencia. Se trata de referentes necesarios para recuperar la función social de la escuela en la construcción, reinvención y fortalecimiento del lazo social; tarea excesivamente compleja pero indispensable para afrontar las turbulencias y cambios intensos de la contemporaneidad.

La educación argentina necesita más memoria. Memoria de lo que se hizo y de lo que se hizo bien. Lamentablemente, a veces transcurre mucho tiempo entre los hechos (silenciados) y su reconstrucción. Y cuando se piensa en soluciones para los problemas actuales — que siempre tienen un carácter inédito ineludible - se desconoce que situaciones similares, y sus respuestas, pueden ser buenos puntos de partida. Santa Fe está hoy en un debate en torno a una Ley Provincial que define derechos, obligaciones e instituciones. Este libro, de narrativa fluida y amena pero con gran contenido teórico y relevancia histórica, se instaura como un insumo más para definir políticas curriculares hoy. 